\title{
CEREMONIA DE INAUGURACIÓN DE LA CENTRAL DE URGENCIAS DEL HOSPITAL INFANTIL UNIVERSITARIO DE SAN JOSÉ, AGOSTO 15 DE 2006
}

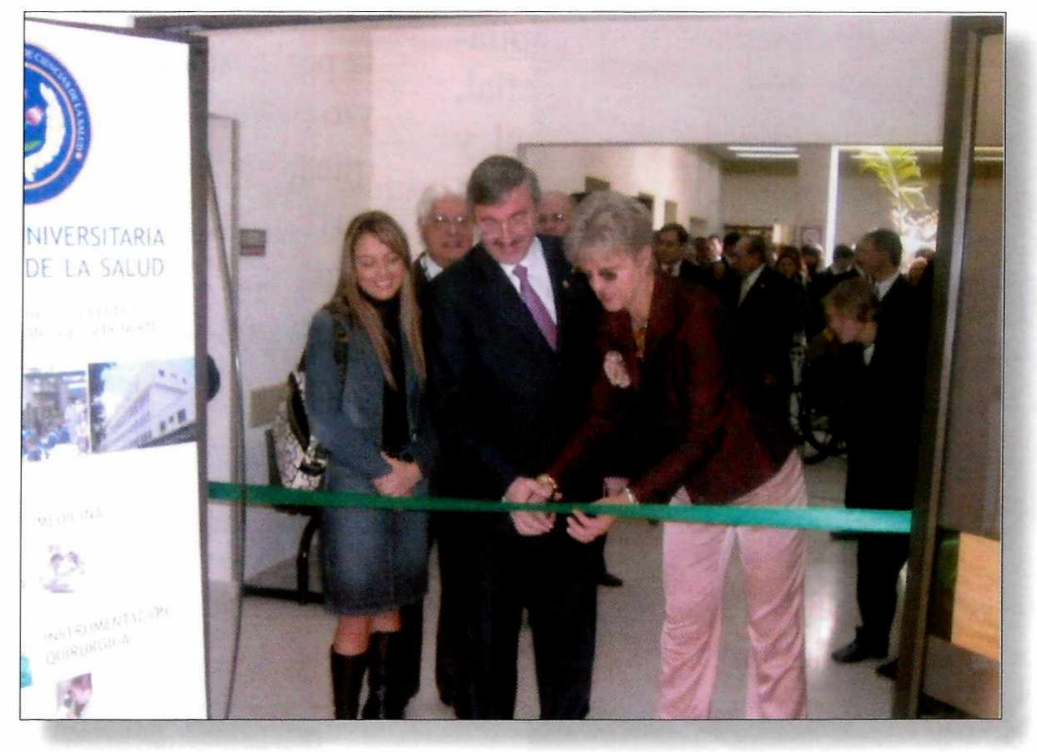

De izquierda a derecha la alcaldesa menor de Barrios los Unidos Dra. María Catherine Mateus, con el Dr. Jorge Gómez Cusnir y la Dra. Laima Didziulis, durante el corte de la cinta inaugural.

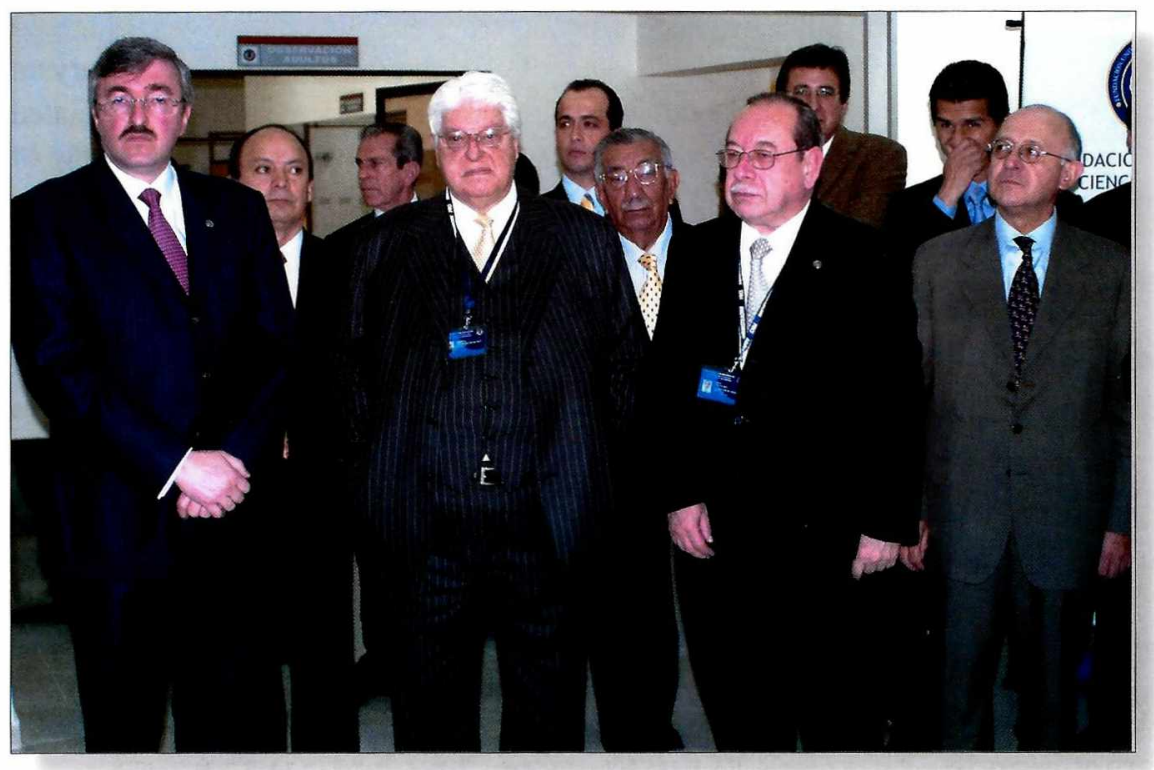

En primer plano de izquierda a derecha los doctores Jorge Gómez Cusnir, Presidente de la Sociedad de Cirugía de Bogotá, Hospital de San José, Roberto Jaramillo Uricoechea, Rector FUCS, Darío Cadena Rey, Vicerrector de Proyectos Especiales, FUCS y Luís Carlos Taborda, Director de Orientación Universitaria FUCS.

En segundo plano de izquierda a derecha los doctores Luís Moya, Manuel Palacios, Rodrigo Pesántez, Guillermo Rueda y Sergio Parra. 


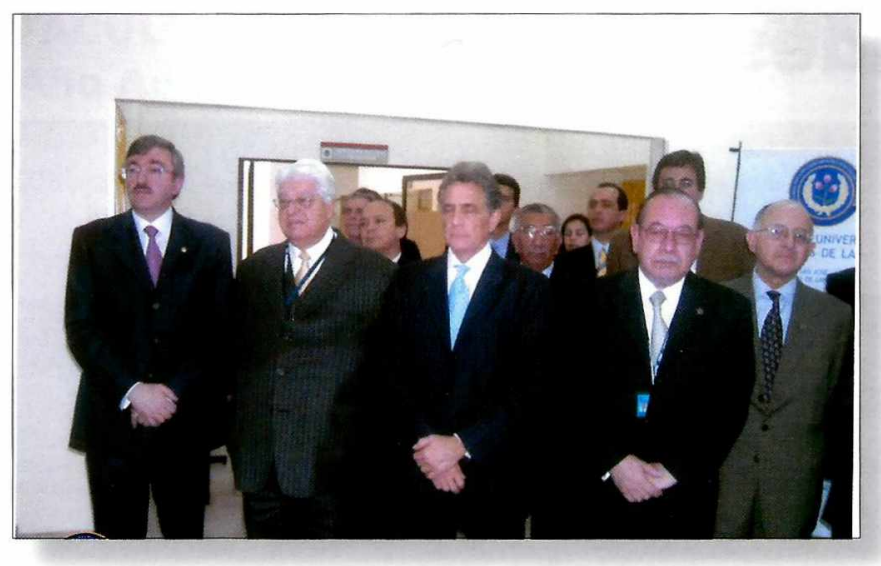

De izquierda a derecha los doctores Jorge Gómez Cusnir, Presidente de la Sociedad de Cirugía de Bogotá, Hospital de San José, Roberto Jaramillo Uricoechea, Rector FUCS, Esteban Díaz-Granados,VicerrectorAdministrativo FUCS, Darío Cadena Rey,Vicerrector de Proyectos Especiales FUCS y Luís Carlos Taborda, Director de Orientación Universitaria FUCS.

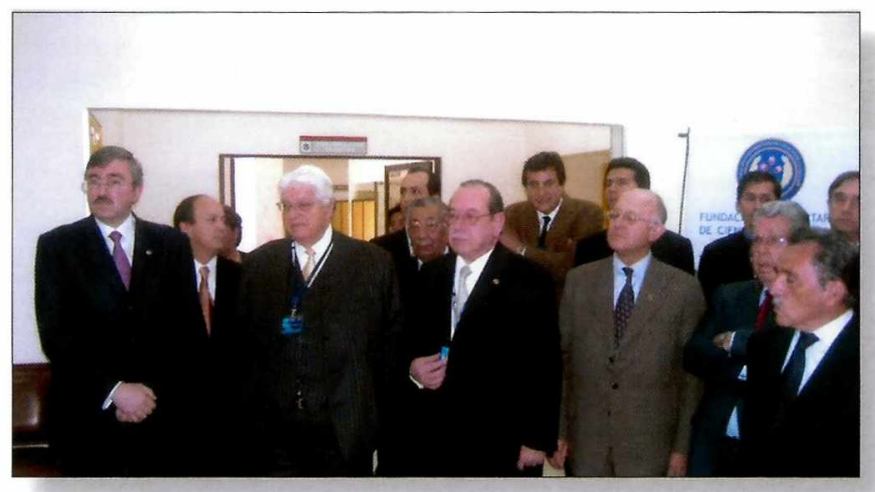

En primer plano de izquierda a derecha aparecen los doctores Jorge Gómez Cusnir, Roberto Jaramillo, Darío Cadena, Luís Carlos Taborda, Hernando Ruiz y Jesús Gómez Palacino. En segundo plano aparecen los doctores Luís Moya, Rodrigo Pesántez, Guillermo Rueda, Sergio Parra y Edgar Olmos.

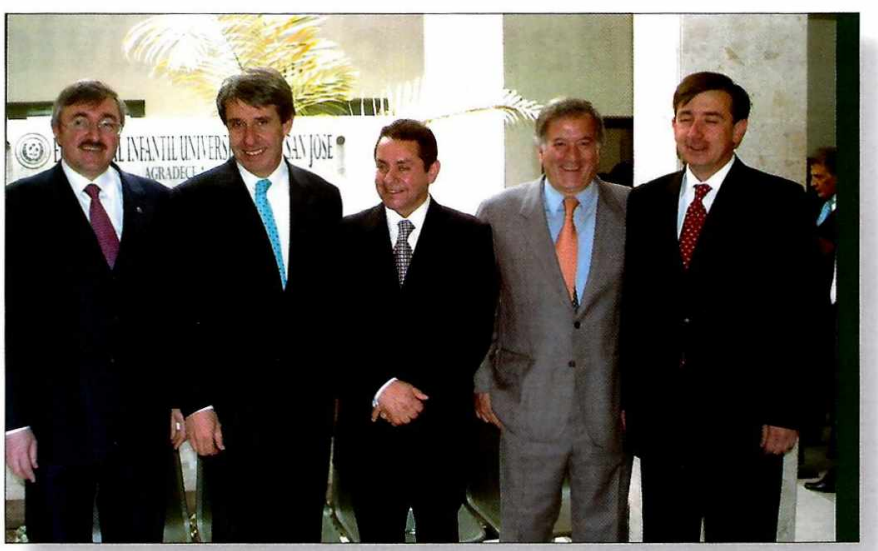

De izquierda a derecha aparecen los doctores Jorge Gómez Cusnir, Presidente de la Sociedad de Cirugía de Bogotá, Hospital de San José,Alberto Ospina Carreño, Presidente de Alfragrés S.A., Hernán Salcedo Cruz, Presidente de Daga S.A. Leonardo Delgado Jaramillo, Gerente General de Alpopular,y Enrique DeFrancisco, Presidente de Alfagrés S.A. Ecuador.

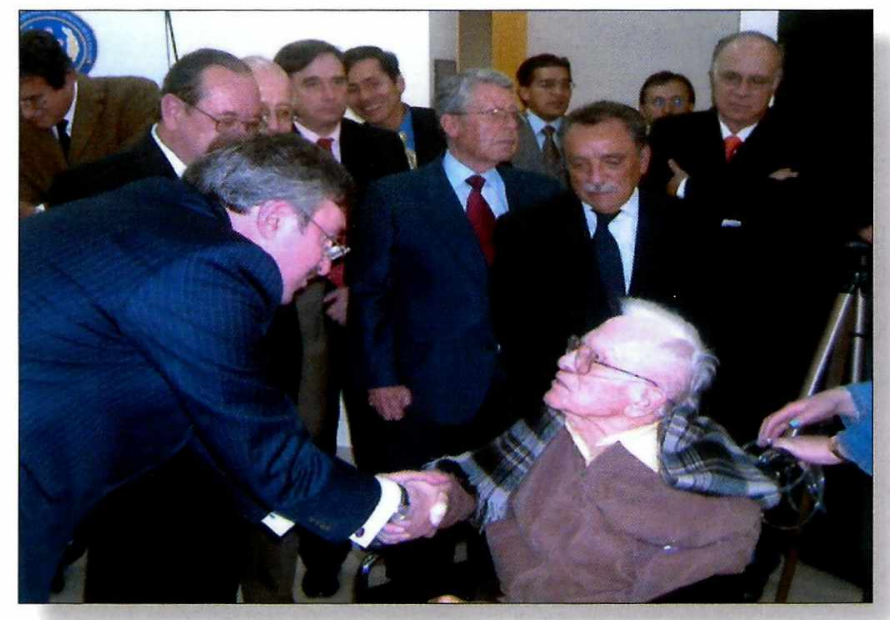

El Dr. Jorge Gómez Cusnir, Presidente de la Sociedad de Cirugía de Bogotá, saluda al profesor Juan Di Doménico, miembro honorario de la Sociedad de Cirugía de Bogotá, Hospital de San José. Observan los doctores Esteban Díaz-Granados, Darío Cadena, Luís Carlos Taborda, Edgar Olmos, Hernando Ruiz, Jesús Gómez Palacino y Luís A. Blanco.
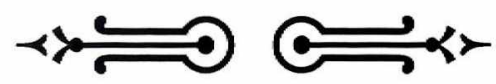